\title{
Mass cytometry defines distinct immune profile in germinal center B-cell lymphomas
}

\author{
Mikael Roussel ${ }^{1,2}$ - Faustine Lhomme ${ }^{2}$. Caroline E. Roe $e^{3,4} \quad$. Todd Bartkowiak ${ }^{3,4} \quad$. Pauline Gravelle ${ }^{5}$. \\ Camille Laurent $^{5}$ - Thierry Fest ${ }^{1,2}$. Jonathan M. Irish ${ }^{3,4}$
}

1 Laboratoire Hématologie, CHU Pontchaillou, Centre Hospitalier Universitaire de Rennes, Pôle Biologie, 2 rue Henri Le Guilloux, 35033 Rennes, France

2 INSERM, UMR U1236, Université Rennes 1, EFS Bretagne, Equipe Labellisée Ligue Contre Le Cancer, Rennes, France

3 Department of Cell and Developmental Biology, Vanderbilt University School of Medicine, 740B Preston Building, 2220 Pierce Avenue, Nashville, TN 37232-6840, USA
4 Department of Pathology, Microbiology and Immunology, Vanderbilt University School of Medicine, Nashville, TN, USA

5 Service Anatomie Et Cytologie Pathologiques and UMR1037, Toulouse, France

\begin{abstract}
Tumor-associated macrophage and T-cell subsets are implicated in the pathogenesis of diffuse large B-cell lymphoma, follicular lymphoma, and classical Hodgkin lymphoma. Macrophages provide essential mechanisms of tumor immune evasion through checkpoint ligand expression and secretion of suppressive cytokines. However, normal and tumor-associated macrophage phenotypes are less well characterized than those of tumor-infiltrating T-cell subsets, and it would be especially valuable to know whether the polarization state of macrophages differs across lymphoma tumor microenvironments. Here, an established mass cytometry panel designed to characterize myeloid-derived suppressor cells and known macrophage maturation and polarization states was applied to characterize B-lymphoma tumors and non-malignant human tissue. Highdimensional single-cell analyses were performed using dimensionality reduction and clustering tools. Phenotypically distinct intra-tumor macrophage subsets were identified based on abnormal marker expression profiles that were associated with lymphoma tumor types. While it had been proposed that measurement of CD163 and CD68 might be sufficient to reveal macrophage subsets in tumors, results here indicated that S100A9, CCR2, CD36, Slan, and CD32 should also be measured to effectively characterize lymphoma-specific tumor macrophages. Additionally, the presence of phenotypically distinct, abnormal macrophage populations was closely linked to the phenotype of intra-tumor T-cell populations, including PD-1 expressing T cells. These results further support the close links between macrophage polarization and T-cell functional state, as well as the rationale for targeting tumor-associated macrophages in cancer immunotherapies.
\end{abstract}

\section{Keywords Germinal center $\cdot$ Lymphoma $\cdot$ Tumor-associated macrophages $\cdot$ Mass cytometry}

\section{Abbreviations \\ APC Allophycocyanin \\ BSA Bovine serum albumin \\ cDC Classical dendritic cells \\ CM Central memory \\ CyTOF Cytometry by time-of-flight}

Parts of the results of this study were presented as poster in

November 2018 at the 1st European Symposium on Myeloid

Regulatory Cells in Health and Disease, in Essen (Germany).

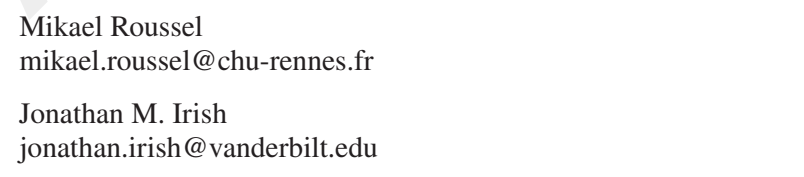

Extended author information available on the last page of the article
DC Dendritic cell

DLBCL Diffuse large B-cell lymphoma 32

EM Effector memory

EMRA Effector memory CD45RA ${ }^{\text {pos }}$

FITC Fluorescein isothiocyanate

FL Follicular lymphoma

G-CSF Granulocyte-colony stimulating factor

GM-CSF Granulocyte macrophage-colony stimulating

factor

HL Hodgkin lymphoma

IDO Indoleamine 2,3-dioxygenase

M_IL10 Macrophage polarized by IL-10

M_IL4 Macrophage polarized by IL-4

M_TPP Macrophage polarized by TPP

M-CSF Macrophage-colony stimulating factor

MDSC Myeloid-derived suppressor cells

mIHC Multiplex immunohistochemistry

N Naive

PBS Phosphate-buffered saline 


$\begin{array}{lll}50 & \text { PD-1 } & \text { Programmed cell death protein 1 } \\ 51 & \text { PD-L1 } & \text { Programmed death-ligand 1 } \\ 52 & \text { pDC } & \text { Plasmacytoid dendritic cell } \\ 53 & \text { PE } & \text { Phycoerythrin } \\ 54 & \text { PFA } & \text { Paraformaldehyde } \\ 55 & \text { HD } & \text { Reactive lymphoid hyperplasia } \\ 56 & \text { S100A9 } & \text { S100 calcium-binding protein A } \\ 57 & \text { Slan } & \text { 6-Sulfo LacNAc } \\ 58 & \text { SPADE } & \text { Spanning-tree progression analysis of density- } \\ 59 & & \text { normalized events } \\ 60 & \text { t-SNE } & \text { T-distributed stochastic neighbor embedding } \\ 61 & \text { TAM } & \text { Tumor-associated macrophage } \\ 62 & \text { TME } & \text { Tumor microenvironment } \\ 63 & \text { TPP } & \text { Cocktail including TNF } \alpha, \text { Pam3CSK4, and } \\ 64 & & \text { prostaglandin E2 } \\ 65 & \text { Treg } & \text { Regulatory T cell } \\ 66 & \text { viSNE } & \text { Visualization of t-distributed stochastic neigh- } \\ 67 & & \text { bor embedding }\end{array}$

\section{Introduction}

The three most common B-cell lymphomas are diffuse large B-cell lymphoma (DLBCL), follicular lymphoma (FL), and classical Hodgkin lymphoma (HL). The abundance of immune cell subsets varies greatly across these B-lymphoma tumors, and T cells, dendritic cells (DC), and tumor-associated macrophages (TAM) from the tumor microenvironment (TME) have all been implicated in disease pathogenesis [1].

Contrasting roles have been defined for DCs and macrophages in B-cell lymphomas. In FL, HL, and DLBCL, plasmacytoid DCs (pDC), CD83 ${ }^{\text {pos }}$ myeloid DCs, and $\mathrm{CD} 1 \mathrm{a}^{\text {pos }}$ DCs, respectively, were correlated with better prognosis, suggesting that DCs are not tolerogenic in lymphoma and may act against the malignant cells [2-4]. In contrast, TAMs have been described as "M2-like", because these cells can share protein expression profiles and suppressive functions with macrophages polarized with IL-4 [5]. However, highly suppressive macrophages obtained in vitro also display contrasting phenotypes from IL-4 polarized "M2-like" cells [6], and so the deprecated term "M2" is not interchangeable with the functional description "suppressor cell". TAMs have historically been defined using CD68 and/or CD163 and characterized according to immunomodulatory functions, which include production of immunosuppressive cytokines, arginase 1, and indoleamine 2,3-dioxygenase (IDO) [5]. Although TAMs have been associated with immunomodulation in some solid tumor types, their functional role has not yet been systematically defined within the lymphoma microenvironment.

In DLBCL and HL, we and others have observed increase in circulating MDSC (myeloid-derived suppressor cells) that were correlated with poor prognosis [7, 8]. Furthermore, murine models of solid tumors have demonstrated that MDSCs can differentiate into TAMs at the tumor site $[5,9$, 10]. The heterogeneous phenotypes of TAMs have recently begun to be characterized in human tumors using highdimensional approaches [11-13]. In DLBCL, FL, and HL, TAMs were traditionally defined using less than five features, characterized as $\mathrm{CD} 68^{\text {pos }}$ or $\mathrm{CD} 68^{\text {pos }} \mathrm{CD} 163^{\text {pos }}$, and interrogated for prognostic significance [14-20]. However, contrasting and incompatible correlations with clinical outcomes were reported for ostensibly the same TAM populations, suggesting that identifying TAMs only as CD68 ${ }^{\text {pos }}$, $\mathrm{CD} 163^{\text {pos }}$, or $\mathrm{CD} 68^{\text {pos }} \mathrm{CD} 163^{\text {pos }}$ is insufficient [21]. Notably, these studies also differed in treatments [21], such as inclusion or not of anti-CD20 therapy, but it is unlikely to fully explain the diametrically opposed functions reported for the TAMs identified by comparable low-dimensional methods.

Herein, we used high-dimensional mass cytometry to decipher the myeloid compartment in lymphoma and to determine which TAM phenotypes were associated with DLBCL, FL, or HL lymphoma tumor type. In addition, phenotypes of other tumor-infiltrating immune cells were also characterized by the mass cytometry antibody panel. A central goal of the study was to further test whether CD163 and/or CD68 expression were sufficient to identify TAMs in B-cell lymphomas and to identify additional proteins that might be valuable for tracking these cells. DLBCLs, FLs, HLs, and reactive healthy tissues were analyzed with a panel of more than 32 antibodies and an analysis pipeline was validated using ex vivo models of myeloid maturation [22]. This approach allowed objective comparisons of TAM subsets between lymphomas and with healthy tissue and revealed that abnormal, phenotypically distinct macrophages were present in each of the three studied lymphoma types.

\section{Material and methods}

\section{Tissue samples}

Twenty-two tissues samples were analyzed, including cells from 16 lymphoma patients ( $n=7$ DLBCL, $n=2 \mathrm{FL}, n=7$ HL) and 6 control samples of reactive lymphoid hyperplasia with no evidence of malignant disease (HD). Tissue from patients was acquired with informed consent in accordance with local institutional review and the Declaration of Helsinki. With one exception, all tissue samples were obtained at diagnosis, before any treatment. The exception, patient sample DLBCL\#1, was obtained at relapse 1 year after the initial diagnosis and following treatment, which included anti-CD20. Diagnoses were performed during the routine workflow by trained hematopathologists. Viable cell suspensions were prepared using a mechanical dissociation (GentleMacs dissociator, Miltenyi Biotec, Bergisch Gladbach, 
Germany), then cells were cryopreserved in FBS (Life Technologies, Grand Island, NY, USA) containing 12\% DMSO (Fischer Scientific, Fair Lawn, NJ, USA).

\section{Antibodies, cell labeling and mass cytometry analysis}

Antibodies conjugation, cell labeling, and mass cytometry analysis steps were performed as previously published [22]. Briefly, purified antibodies were purchased from Biolegend (San Diego, CA, USA) or Immunotech (Marseille, France) and were labeled using MaxPar DN3 labeling kits according to protocol (Fluidigm, San Francisco, CA, USA). Antibodies from Miltenyi Biotec (Bergisch Gladbach, Germany) or R\&D systems (Minneapolis, MN, USA) were labeled with FITC (fluorescein isothiocyanate), PE (phycoerythrin), or APC (allophycocyanin) (Table S1). Metal-conjugated primary antibodies as well as secondary antibodies targeting FITC, PE, or APC were purchased from Fluidigm. After thawing, cells were incubated with a viability reagent (cisplatin, $25 \mu \mathrm{M}$; Enzo Life Sciences, Farmingdale, NY, USA) as previously described [23]. Then, $3 \times 10^{6}$ cells were washed in phosphate-buffered saline (PBS, HyClone Laboratories, Logan, UT, USA) containing $1 \%$ bovine serum albumin (BSA, Fisher Scientific, Fair Lawn, NJ, USA) and stained for $30 \mathrm{~min}$ in $50 \mu \mathrm{L}$ PBS and 1\% BSA containing a master mix of the antibodies used for surface staining (Table S1). After washing, cells were stained with an anti-FITC metaltagged antibody. Then, cells were washed twice in PBS and $1 \%$ BSA and before fixation with $1.6 \%$ paraformaldehyde (PFA, Electron Microscopy Sciences, Hatfield, PA, USA). Cells were washed once in PBS and permeabilized by resuspending in ice cold methanol. After incubating overnight at $-20^{\circ} \mathrm{C}$, cells were washed twice with PBS and $1 \%$ BSA. Cells were then stained with intracellular antibodies. Finally, cells were stained with anti-PE and anti-APC metal-tagged antibody. After washing, cells were stained with an iridium DNA intercalator (Fluidigm) for $20 \mathrm{~min}$ at room temperature. Finally, cells were resuspended in $1 \times \mathrm{EQ}^{\mathrm{TM}}$ Four Element Calibration Beads (Fluidigm). Analysis was performed on a CyTOF 1.0 mass cytometer (Fluidigm) at Vanderbilt University. Samples were collected in four batches (Table S2). After acquisition and before analysis, all samples were normalized across batches with $\mathrm{EQ}^{\mathrm{TM}}$ Four Element Calibration beads as previously described [24]. Absence of batch effect was checked by visualization of viSNE from each run of analysis (Figure S1). Raw mass cytometry data are accessible at Flow Repository (FR-FCM-Z2CA).

\section{In vitro polarization of macrophages}

We compared the phenotype of the myeloid modules to in vitro polarized macrophages already published by our group [22]. Briefly, macrophages were generated by stimulating monocytes with M-CSF (macrophage-colony stimulating factor, $50 \mathrm{ng} / \mathrm{mL}$; Cell Signaling, Danvers, MA, USA) for 3 days, as previously described [6]. Then, the macrophages were further polarized for 3 days, with IL-4, IL-10 (10 ng/mL each; Peprotech, Rocky Hill, NJ, USA), or TPP cocktail including TNF $\alpha(10 \mathrm{ng} / \mathrm{mL}$; MilliporeSigma, St Louis, MA, USA), the toll-like receptor 2 agonist Pam3CSK4 (100 ng/mL; Invivogen, San Diego, CA, USA) and, prostaglandin E2 (1 $\mu \mathrm{g} / \mathrm{mL}$, MilliporeSigma). MDSCs were derived from monocytes cultured for 4 days with GMCSF (granulocyte macrophage-colony stimulating factor, 40 ng/mL; Peprotech,) and G-CSF (granulocyte-colony stimulating factor, $40 \mathrm{ng} / \mathrm{mL}$; Peprotech). Before hierarchical cluster analysis, raw files from the polarization experiments were normalized with tissues samples with $\mathrm{EQ}^{\mathrm{TM}}$ Four Element Calibration Beads as previously described [24].

\section{Data processing and analysis}

Data analysis was performed using the workflow previously developed (Figure S2) [22, 25, 26]. Briefly, raw median intensity values were transformed to a hyperbolic arcsine (arcsinh) scale with a cofactor of 5, then analysis was performed using Cytobank software (Beckman Coulter, Brea, CA, USA) [27]. Each file was pre-gated as is standard in the field for single, viable cells, as defined by cisplatin (viability) and iridium (nucleic acid). Then, the viSNE (visualization of t-distributed stochastic neighbor embedding, t-SNE) was performed to identify cell types. The default settings were used to create the t-SNE map (perplexity $=30$, iterations $=1000$, theta $=0.5$ ) and all channels in which antibodies were used were included in mapping. On the t-SNE map, B-cell (B; CD $\left.19^{\text {pos }} \mathrm{CD} 3^{\text {neg }}\right)$, CD4 T-cell (TCD4; CD $3^{\text {pos }} \mathrm{CD}^{\text {neg }}$ ), CD8 T-cell (TCD8; CD $3^{\text {pos }} \mathrm{CD}^{\text {pos }}$ ), NK cell (NK; CD45RA ${ }^{\text {pos }} \mathrm{CD} 16^{\mathrm{pos}} \mathrm{CD} 3^{\text {neg }}$ ), and myeloid cell (My; $\mathrm{CD} 3^{\text {neg }} \mathrm{CD} 19^{\text {neg }}$, either $\mathrm{CD} 14^{\text {pos }}, \mathrm{CD} 36^{\text {pos }}, \mathrm{CD} 123^{\text {pos }}$, or $\left.\mathrm{CD} 11 \mathrm{c}^{\mathrm{pos}}\right)$ populations were gated. These populations were exported as separate flow cytometry standard files (fcs). Myeloid cells were concatenated in a single fcs file containing 55,066 events (Table S2). Each cell was identified in the fcs file with the ID of the tissue of origin. A new, common t-SNE map was created and then clustering was performed by SPADE (spanning-tree progression of density-normalized events) using 200 cluster nodes, and clustering on the t-SNE1 ( $t$-distributed stochastic neighbor embedding) and t-SNE2 channels to objectively and computationally separate apparent myeloid cell subsets. Nodes with fewer than ten cells were discarded. Modules were identified by hierarchical clustering of mean marker intensity on each SPADE cluster representing a phenotypically distinct myeloid cell population. 
Each fcs file containing $\mathrm{T}$ lymphocytes was analyzed by a similar SPADE analysis using 50 clustering nodes and clustering on the t-SNE1 and t-SNE2 channels. The following cell clusters were defined by SPADE: Tregs $\left(\mathrm{CD} 3^{\text {pos }} \mathrm{CD} 8^{\text {neg }} \mathrm{CD} 25^{\text {pos }} \mathrm{CD} 127^{\text {low }}\right)$, naïve $\mathrm{CD} 4 \mathrm{~T}$ cells (T4N; $\mathrm{CD} 3^{\text {pos }} \mathrm{CD} 8^{\text {neg }} \mathrm{CD} 45 \mathrm{RA}{ }^{\text {pos }} \mathrm{CCR} 7^{\text {pos }}$ ), naïve CD8 T cells (T8N; CD $3^{\text {pos }} \mathrm{CD} 8^{\text {pos }}{ }^{\text {CD }} 45 \mathrm{RA}^{\text {pos }} \mathrm{CCR} 7^{\text {pos }}$ ), central memory CD4 T cells (T4CM; $\left.\mathrm{CD} 3^{\text {pos }} \mathrm{CD} 8^{\text {neg }} \mathrm{CD} 45 \mathrm{RA}{ }^{\text {neg }} \mathrm{CCR} 7^{\text {pos }}\right)$, central memory CD8 T cells (T8CM; $\mathrm{CD} 3^{\text {pos }} \mathrm{CD} 8^{\text {pos }} \mathrm{CD} 45 \mathrm{RA}{ }^{\text {neg }} \mathrm{CCR} 7^{\text {pos }}$ ), effector memory CD4 $\mathrm{T}$ cells (T4EM; $\left.C D 3^{\text {pos }} C D 8^{\text {neg }} C D 45 R A^{\text {neg }} C C R 7^{\text {neg }}\right)$, effector memory CD8 T cells (T8EM; CD $3^{\text {pos }} \mathrm{CD}^{\mathrm{pos}} \mathrm{CD} 45 \mathrm{RA}{ }^{\text {neg }} \mathrm{CCR} 7^{\text {neg }}$ ), effector memory CD45RA ${ }^{\text {pos }} \mathrm{CD} 4 \mathrm{~T}$ cells (T4EMRA; $\left.\mathrm{CD} 3{ }^{\text {pos }} \mathrm{CD} 8^{\text {neg }} \mathrm{CD} 45 \mathrm{R} \mathrm{A}^{\text {pos }} \mathrm{CCR} 7^{\text {neg }}\right)$, and effector memory CD45RA ${ }^{\text {pos }}$ CD8 $\mathrm{T}$ cells (T8EMRA; $\left.\mathrm{CD} 3^{\text {pos }} \mathrm{CD} 8^{\text {pos }} \mathrm{CD} 45 \mathrm{RA}^{\mathrm{pos}} \mathrm{CCR} 7^{\text {neg }}\right)$.

The main parameters defining the lymphoma types were defined on a biaxial plot analysis using a matrix of the frequencies for each cell subset (STATA 13, StataCorp, College Station, TX, USA).

\section{Multiplex immunohistochemistry (mIHC)}

Samples were fixed in $10 \%$ buffered formalin, embedded in paraffin and processed for routine histopathological examination. For quadruple immunofluorescence staining, 4- $\mu$ m-thick sections were loaded on the Ventana Discovery ULTRA (Ventana Medical Systems, Tucson, AZ, USA). After dewax and pretreatment, slides were incubated with primary antibodies CD68 (clone KP-1, Ventana), CD206 (polyclonal, Abcam, Cambridge, UK), CD16 (clone SP175, Ventana) and S100A9 (Clone EP185, Bio SB, Santa Barbara, CA, USA) or CD163 (clone MRQ-26, Ventana). Primary antibodies were visualized using the OmniMap-HRP (Horse radish peroxidase conjugated anti-rabbit, anti-mouse) secondary system and tyramide-conjugated fluorophore kits FAM, Rhodamin6G, Red 610 and Cy5 (Ventana). Counterstain was performed using Hoechst 33342 (Thermo Fisher Scientific, Waltham, MA, USA). Whole slides of mIHC-stained PBL were scanned using Panoramic digital slide scanner (3DHISTECH, Budapest, Hungary) equipped with appropriate filters sets [28].

\section{Statistical analysis}

Statistical analyses were performed with GraphPad Prism 5.0 software (GraphPad Software, San Diego, CA, USA). A Mann-Whitney test and Spearman correlation were used to compare differences between groups. For correlations between immune cell populations, matrix calculations were performed between frequencies of cell subsets (in column) and samples (in row), for each type of sample (FLBCL, HL, or HD). A Spearman correlation was then calculated for each cell subset. For all statistical tests, $p<0.05$ was considered statistically significant.

\section{Results}

Mass cytometry delineated T, NK, and myeloid cells within B-lymphoma tumor and healthy tissues

To dissect the heterogeneity of the tumor microenvironment, tumors from DLBCL $(n=7)$, FL $(n=2)$, or HL $(n=7)$ were compared to each other and reactive lymph node tissue (HD, $n=6$ ). Patients' characteristics are summarized in Table 1. A total of 1,863,184 cells were analyzed (Table S2). For each sample, $\mathrm{B}\left(\mathrm{CD} 19^{\text {pos }} \mathrm{CD} 3^{\text {neg }}\right)$, TCD4 $\left(\mathrm{CD} 3^{\text {pos }} \mathrm{CD} 8^{\text {neg }}\right)$, TCD8 $\left(\mathrm{CD} 3^{\text {pos }} \mathrm{CD} 8^{\text {pos }}\right)$, NK $\left(\mathrm{CD} 45 \mathrm{RA}^{\text {pos }} \mathrm{CD} 16^{\text {pos }} \mathrm{CD} 3^{\text {neg }}\right)$, and myeloid cells (My, $\mathrm{CD} 3^{\text {neg }} \mathrm{CD} 19^{\text {neg }}$ and $\mathrm{CD} 14^{\text {pos }}$, or $\mathrm{CD} 36^{\text {pos }}$, or $\mathrm{CD} 123^{\text {pos }}$, or $\mathrm{CD} 11 \mathrm{c}^{\mathrm{pos}}$ ) were defined on a viSNE map (Fig. 1a). B cells were the most abundant population in DLBCL and FL samples (median frequency at $65.5 \%$ and $56.7 \%$, respectively) when compared to HL and HD samples (median frequency at $35.2 \%$ and $39.2 \%$, respectively) (Fig. 1b). CD4 T lymphocytes were reduced in DLBCL (median at $21.9 \%$ vs $32.2 \%, 37.8 \%$, and $39.5 \%$ for FL, HL, and HD, respectively). CD8 $\mathrm{T}$ lymphocytes were observed at a median frequency of 9.4\%, 10.4\%, 19.2\%, and $16.2 \%$, for DLBCL, FL, HL, and HD, respectively. NK cells were rarely detected amongst all tumor types (median frequency between 0 and $0.5 \%$ ). Finally, myeloid cells were detected at low frequencies (median frequency between 0.6 and $4.2 \%$ ) in all samples analyzed.

\section{Multiple TAM subsets were increased in lymphomas}

The in-depth analysis began with the myeloid compartment. The mass cytometry panel was specifically designed to recognize and deeply characterize myeloid cell types and polarization states within monocytes, TAMs, and DCs [22]. Jointly, 55,066 myeloid cells $\left(\mathrm{CD} 3^{\text {neg }} \mathrm{CD} 19^{\text {neg }}\right.$ and CD $14^{\text {pos }}$, or $\mathrm{CD} 36^{\mathrm{pos}}$, or $\mathrm{CD} 123^{\mathrm{pos}}$, or $\mathrm{CD} 11 \mathrm{c}^{\mathrm{pos}}$ ) from 22 tissue samples (as defined in Fig. 1a) were analyzed from reactive and lymphoma samples (Table S2) using viSNE analysis (Figure S3a). This analysis followed the single-cell methods developed previously for canonically polarized myeloid cell subsets [26]. Median marker expression within clusters obtained by SPADE was visualized by hierarchical clustering (Fig. 2a, Figure S3b, and Figure S3c). Eight modules were defined, including cDC (classical dendritic cells), pDC, and six populations of macrophages (Mac 1-Mac 6) (Fig. 2a and Figure $\mathrm{S} 2 \mathrm{~b}$ ). Interestingly, the relative distribution of myeloid subsets was different for DLBCLs and HLs when compared to HDs. DLBCL and HL displayed higher than normal macrophage frequencies (within the myeloid cell population, median frequencies were $60.5 \%$ for DLBCL and $72.5 \%$ in HL vs. 323 
Table 1 Patients' characteristics

\begin{tabular}{|c|c|c|c|c|c|}
\hline Disease/sample & Patient ID & $\begin{array}{l}\text { Age at diagno- } \\
\text { sis (years) }\end{array}$ & $\begin{array}{l}\text { Gender } \\
\text { (female/ } \\
\text { male) }\end{array}$ & $\begin{array}{l}\text { Cell of origin (DLBCL) or } \\
\text { subtype (HL) or grade (FL) }\end{array}$ & Tissue \\
\hline \multirow[t]{7}{*}{ DLBCL } & $\# 1$ & 76 & F & $\mathrm{ABC}$ & $\mathrm{LN}$ \\
\hline & $\# 2$ & 66 & $\mathrm{M}$ & GC & LN \\
\hline & \#3 & 58 & $\mathrm{M}$ & - & LN \\
\hline & \#4 & 57 & $\mathrm{~F}$ & $\mathrm{ABC}$ & $\mathrm{LN}$ \\
\hline & $\# 5$ & 56 & $\mathrm{~F}$ & $\mathrm{ABC}$ & $\mathrm{LN}$ \\
\hline & $\# 6$ & 65 & $\mathrm{~F}$ & GC & Thyroid \\
\hline & \#7 & 64 & F & GC & $\mathrm{LN}$ \\
\hline \multirow[t]{7}{*}{ HL } & $\# 1$ & 26 & M & NSHL & $\mathrm{LN}$ \\
\hline & \#2 & 49 & M & LRCHL & LN \\
\hline & $\# 3$ & 48 & M & MCHL & $\mathrm{LN}$ \\
\hline & \#4 & 68 & M & MCHL & $\mathrm{LN}$ \\
\hline & $\# 5$ & 22 & M & NSHL & $\mathrm{LN}$ \\
\hline & \#6 & 50 & M & $\mathrm{cHL}$ & $\mathrm{LN}$ \\
\hline & \#7 & 49 & $\mathrm{~F}$ & NSHL & $\mathrm{LN}$ \\
\hline \multirow[t]{2}{*}{ FL } & $\# 1$ & 48 & M & $3 \mathrm{a}$ & $\mathrm{LN}$ \\
\hline & $\# 2$ & 47 & $\mathrm{~F}$ & $1-2$ & $\mathrm{LN}$ \\
\hline \multirow[t]{6}{*}{ HD } & $\# 1$ & 50 & M & - & $\mathrm{LN}$ \\
\hline & $\# 2$ & 35 & M & - & $\mathrm{LN}$ \\
\hline & \#3 & 36 & $\mathrm{~F}$ & - & $\mathrm{LN}$ \\
\hline & \#4 & 26 & M & - & $\mathrm{LN}$ \\
\hline & $\# 5$ & 35 & $\mathrm{~F}$ & - & $\mathrm{LN}$ \\
\hline & $\# 6$ & 52 & $\mathrm{~F}$ & - & Tonsil \\
\hline
\end{tabular}

$D L B C L$ diffuse large B-cell lymphoma, $A B C$ activated B cell, $G C$ germinal center, $c H L$ classical Hodgkin lymphoma, NSHL nodular sclerosis Hodgkin lymphoma, $L R C H L$ lymphocyte rich cHL, MCHL mixed cellularity Hodgkin lymphoma, $L N$ lymph node

$23.4 \%$ in healthy, $p<0.05)$ and lower pDC frequencies $(0 \%$ in DLBCL and $27.5 \%$ in HL vs. $76.4 \%$ in healthy, $p<0.05$ ) (Fig. 2b). Furthermore, macrophage modules (Mac1-Mac6) were also differentially expressed between lymphomas and reactive nodes (Fig. 2c). DLBCLs contained populations Mac1 (4 cases out of 7) or Mac5 (2 cases out of 7). One DLBCL patient's tumor contained a mix of computationally identified cDC, Mac1, Mac2, and Mac4 cell subsets. In contrast, FL patient's tumors contained a mix of $\mathrm{cDC}$, Mac1, and Mac4 and, variably, Mac5. HLs included Mac1, Mac3, and Mac6. Of note, Mac3 and Mac6 were present only in HLs (Fig. 2c). In HDs, pDC represented the majority of myeloid modules, except for one case highly enriched in Mac2.

Next, the phenotype of these modules was analyzed across lymphomas. In DLBCL, the Mac1 module expressed high amounts of CD14, CD32, CD64, HLA-DR, CD11b, CCR2; S100A9 (S100 calcium-binding protein A9), and CD163, whereas Mac5 expressed CD32, HLA-DR, Slan (6-Sulfo LacNAc), and CD45RA (Fig. 3a). In HL, Mac 1 was positive for CD14, CD32, CD64, CD11b, CCR2, and S100A9; Mac3 cluster expressed CD32, HLA-DR, CD11b, and S100A9; finally, Mac6 expressed CD16 and was HLA-DR ${ }^{\text {low }}$ (Fig. 3a). In DLBCL, CD163 expression by TAMs was confirmed by multiplex IHC (mIHC) (Fig. 3b). Some TAMs expressed also CD16, but few cells co-expressed CD16/CD163 or CD16/ S100A9. In HL, CD16 ${ }^{\text {pos }}$ TAMs were evidenced by mIHC, and significant expression of S100A9 was also noted (Fig. 3b), as in FL (Figure S4). The Mac1 subset found in HL expressed less CD163 than in DLBCL. The Mac3 population in HL expressed high levels of S100A9, whereas Mac6 expressed high levels of CD16 (Fig. 3b, c).

Finally, the phenotype of Mac clusters infiltrating human lymphomas was compared to that of in vitro polarized macrophages or MDSCs [22, 26]. Polarized macrophage signatures were obtained previously under various stimuli (M_IL4, M_IL10, and M_TPP. Mac1 and M_IL10 shared similar phenotype, in particular regarding the expression of CCR2 (Fig. 3d). The Mac4 cluster phenotypically resembled the $\mathrm{M}_{-}$ IL4 phenotype (in particular demonstrating similar expression patterns of CD64, CD163, CD16, HLA-DR, and CD274) as well as in vitro-derived MDSC (in particular showing similar expression levels of CD86). Finally, Mac3, Mac5, and Mac6 were most closely aligned with M_TPP polarized cells. In particular, the Mac3 subset expressed relatively high expression of S100A9 consistent with in vitro TPP polarization (Fig. 3d and Figure S5). 

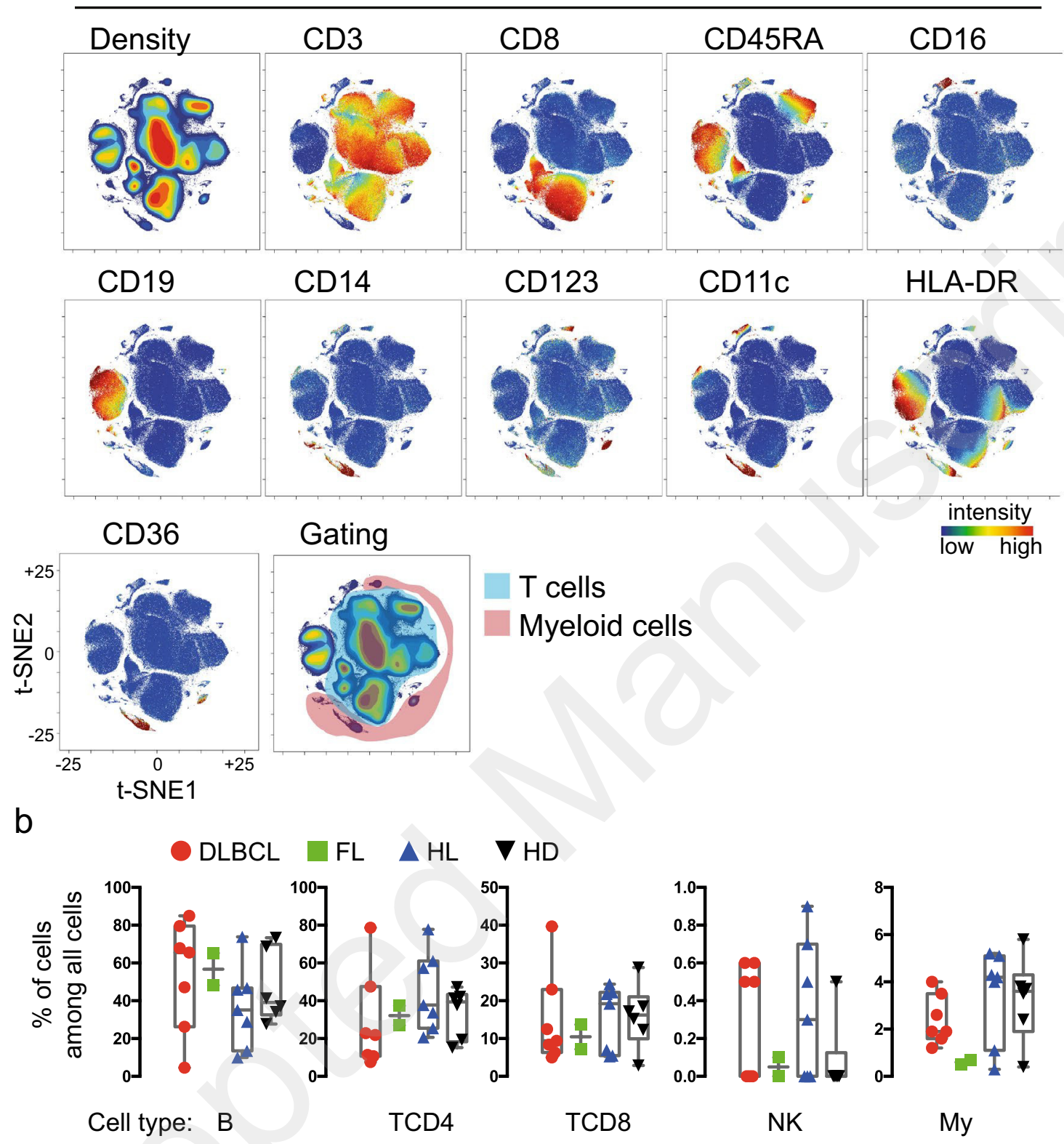

Fig. 1 Myeloid (My), T, and NK cells are detected by mass cytometry within tumor and reactive tissues. a A viSNE is shown for one representative DLBCL tissue. Density plot, CD3, CD8, CD45RA,

CD16, CD19, CD14, CD123, CD11c, and HLA-DR are shown. b Cell subsets frequencies among all viable cells are shown for DLBCL ( $n=7$, red), FL ( $n=2$, green), HL ( $n=7$, blue), and HD ( $n=6$, black)

\section{T-lymphocyte subsets are specific to lymphoma subtypes}

Analysis of T-cell subsets included Tregs $\left(\mathrm{CD} 3{ }^{\text {pos }} \mathrm{CD} 8^{\text {neg }} \mathrm{CD} 25^{\text {pos }} \mathrm{CD} 127^{\text {low }}\right.$ ), naïve $\mathrm{T}$ cells ( $\mathrm{T} 4 \mathrm{~N}$ and $\mathrm{T} 8 \mathrm{~N}$; CD45RA ${ }^{\mathrm{pos}} \mathrm{CCR}^{\mathrm{pos}}$ ), central memory T cells (T4CM and T8CM, CD45RA ${ }^{\text {neg }} C C R 7^{\text {pos }}$ ), effector memory T cells (T4EM and T8EM; CD45RA ${ }^{\text {neg }} C C R 7^{\text {neg }}$ ), and effector memory cells (T4EMRA and T8EMRA; CD45RA ${ }^{\text {pos }} C C R 7^{\text {neg }}$ ) that were defined by SPADE analysis (Fig. 4a). DLBCL 398 samples were characterized by high frequencies of T4CM, 399 T8CM and T8EM when compared to HLs or HDs $(p<0.05), \quad 400$ whereas T4N and T4EMRA frequencies were low when 401 compared to HDs $(p<0.05)$. HLs were defined by low fre- 402 quencies of T4CM, T8CM, and T4EMRA when compared 403 to DLBCLs or HLs $(p<0.05)$. No significant difference was 404 observed for frequencies of Tregs when comparing T-cell 405 populations across lymphoma types (Fig. 4b). Further, a 406 
a

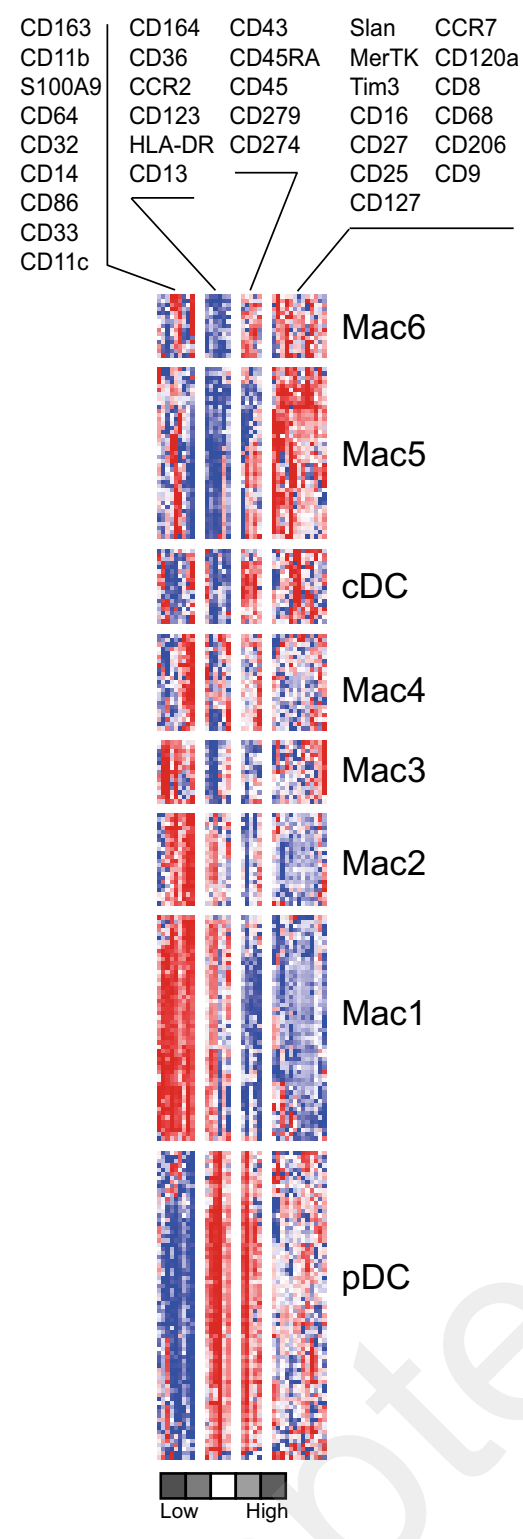

b

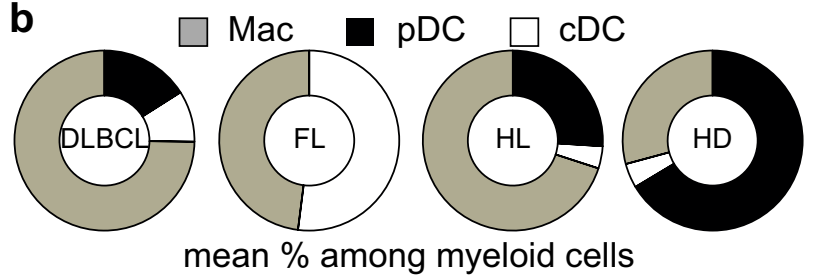

mean $\%$ among myeloid cells

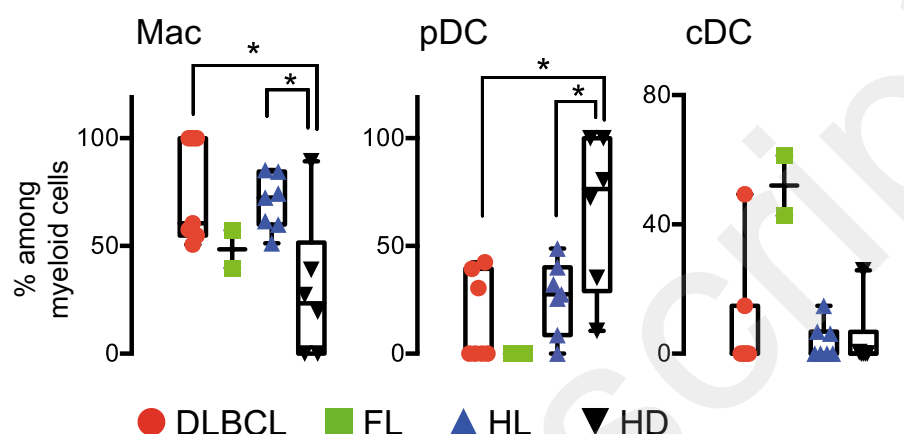

C
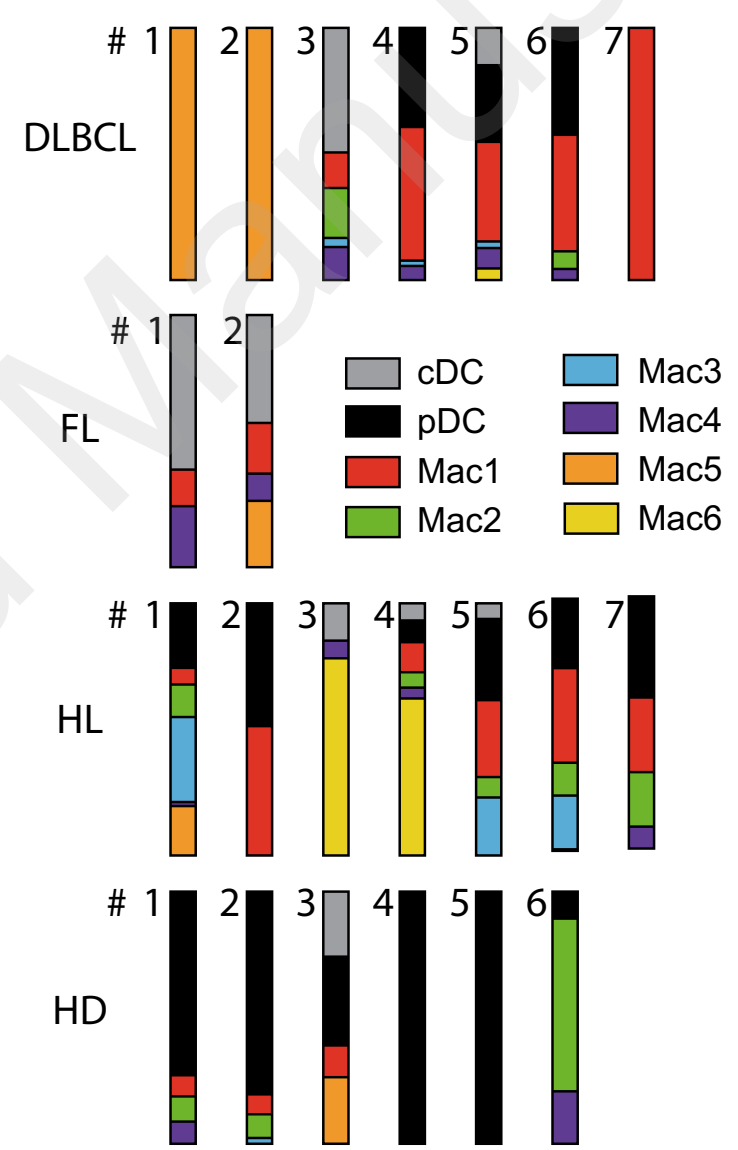

rophages (Mac) and dendritic cells (cDC and $\mathrm{pDC}$ ) among lymphomas (DLBCL, FL, and HL) and reactive tissue (HD). Mac denotes the sum of all macrophage subsets (Mac 1-6). c Distribution of myeloid modules among lymphomas (DLBCL, FL, and HL) and HD. $* p<0.05$
Fig. 2 The lymphoma myeloid compartment was heterogeneous and related to the cancer subtype. a Myeloid cells from lymphomas and reactive tissues were analyzed by hierarchical clustering. Each row corresponds to a SPADE node. Relative normalized transformed mean intensity is presented. Module separation was based on the unsupervised clustering (Figure S3c). b Distribution of mac- 
a

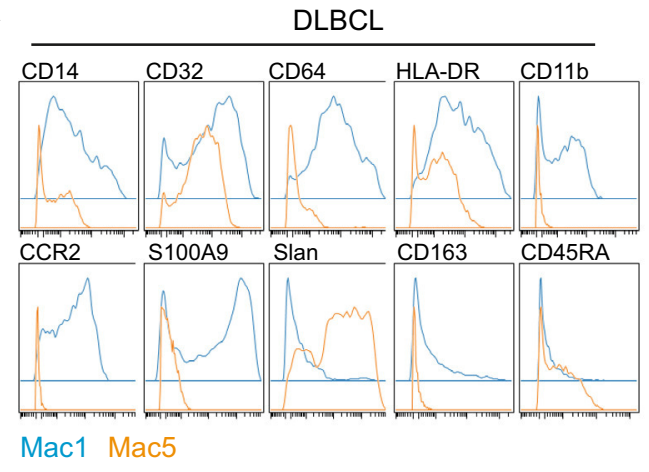

b
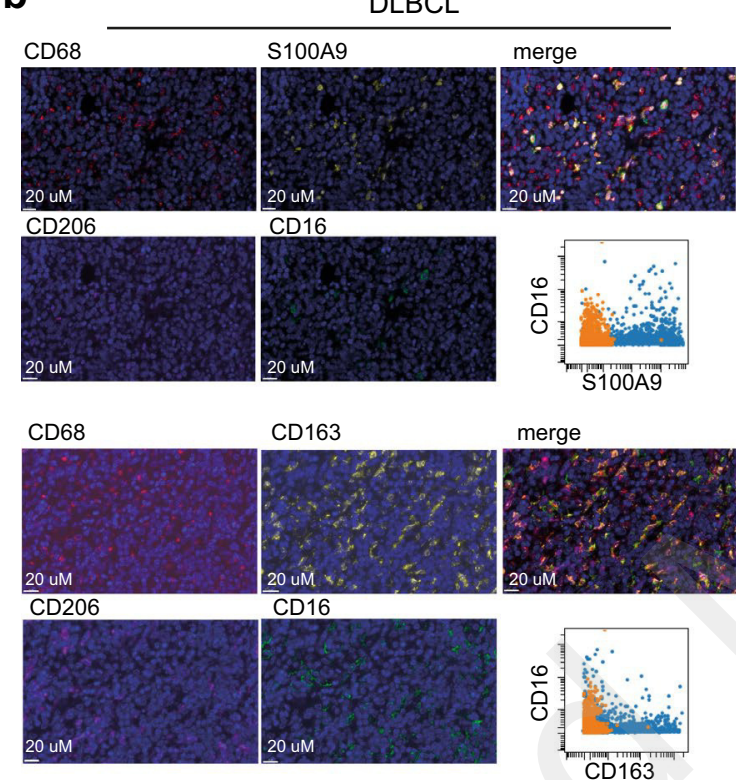

Mac1 Mac5
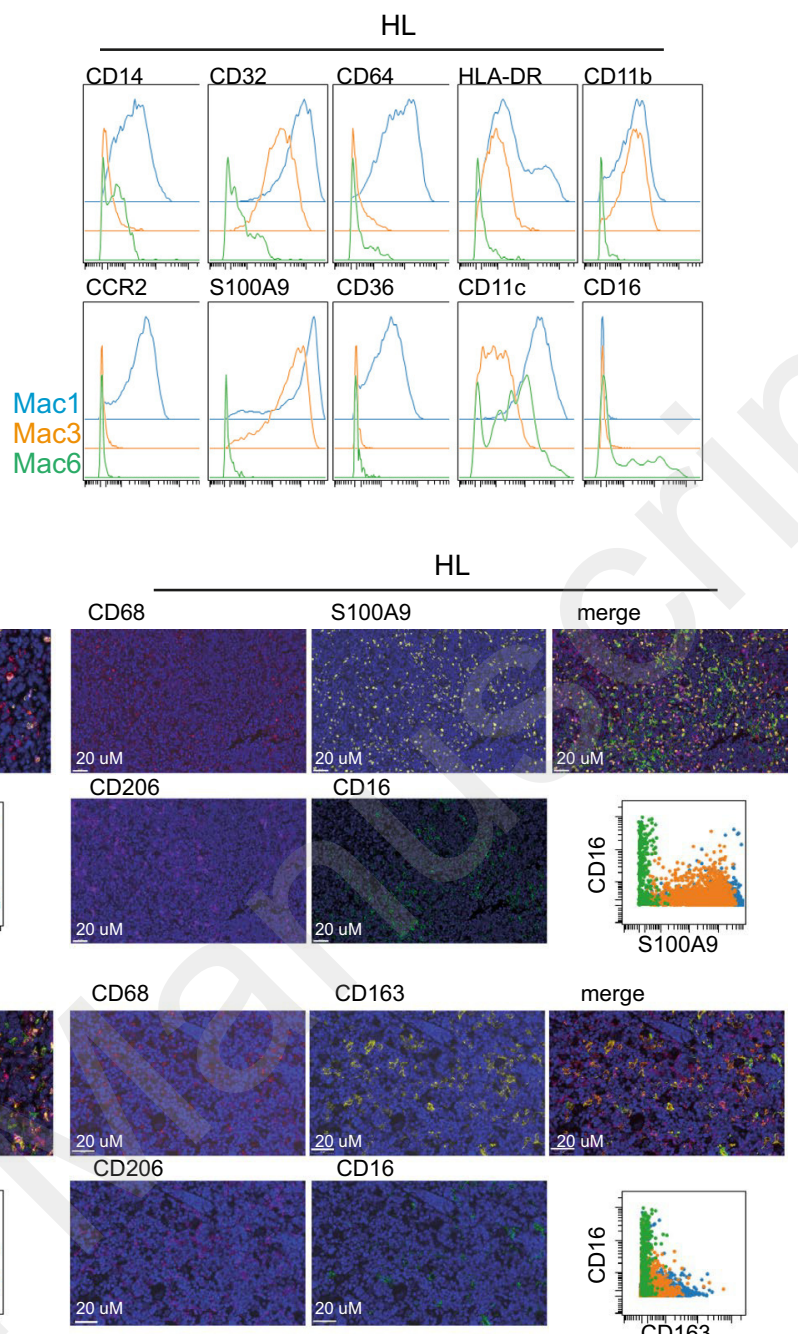

merge
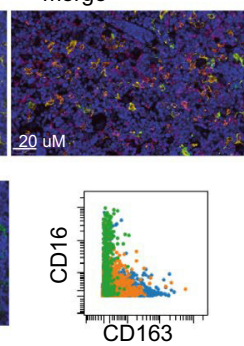

Mac1 Mac3 Mac6

d

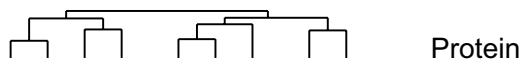

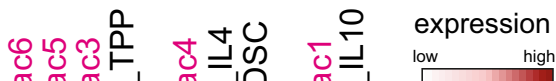
$\sum \sum \sum^{\infty} \Sigma \sum^{\pi} \Sigma \Sigma \sum^{\infty} \Sigma$
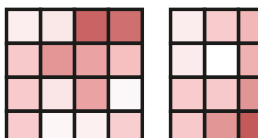

\begin{tabular}{|l|l|}
\hline & \\
\hline & \\
\hline & \\
\hline & \\
\hline & \\
\hline & \\
\hline & \\
\hline & \\
\hline
\end{tabular}

S100A9 CD32 CD64
CCR2
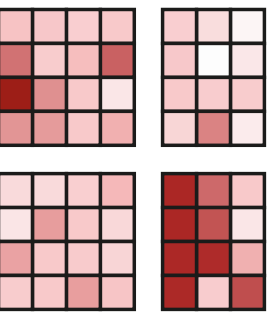

CD163 CD14 CD16 CD120a
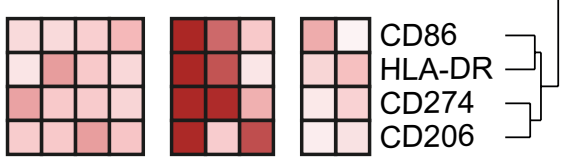
4Fig. 3 Myeloid subsets exhibit specific inflammatory and/or suppressive phenotypes in the lymphoma TME. a Marker expression for Mac modules in DLBCL and HL. b mIHC staining for DLBCL and HL. Bottom right of each panel: Dot plot showing the coexpression of markers for Mac modules defined in Fig. 2. c Top: counts of cell from the mIHC staining for DLBCL $(n=3)$ and HL $(n=3)$ and bottom: percentage of coexpression. In each panel, expression of markers defined by mass cytometry for various Mac subsets. d Heat map after hierarchical clustering for Mac clusters involved in lymphoma (in red) and polarized macrophages (in black). Polarized macrophage signatures were obtained previously under various stimuli (M_IL4, M_IL10, and M_TPP) [22]

greater frequency of PD-1 $1^{\text {pos }}(C D 279 /$ programmed cell death protein 1) T4EM, T4CM, and T8EM cells infiltrated DLBCL compared to HLs $(\mathrm{p}<0.05)$ (Fig. 4c).

\section{Immune landscapes define lymphoma subtypes}

The main cell populations categorizing the samples were defined by biaxial analysis (Figure S6) and, overall, lymphoma samples were well separated from HDs $(p<0.05)$. Within the TME, DLBCL samples were characterized by a high abundance of Mac1, Mac5, T8EM, and T4EM, whereas FLs had high counts of Mac4 and CDC and HLs exhibited a high abundance of Mac6, T8EM, and T4EM. Finally, HDs were characterized by high frequencies of pDC, T4N, T8N, and TEMRA (Figure S6). Finally, to establish relationships between immune cell populations across lymphoma subtypes, the correlation of quantification of these populations across lymphoma subtypes was calculated (Fig. 5). In DLBCL samples, the observed pattern included an increase in Mac5, T8CM, T8EM, Treg, and T4EM and T8EM expressing PD-1 for two patients (\#1 and \#2) out of seven. On the other hand, for five DLBCL patients (\#3, \#4, \#5, \#6, and \#7) out of seven, Mac1 and T4EM were inversely correlated with T4EM expressing PD-1. Interestingly, Mac1 and Mac5 were inversely correlated (Fig. 5). For HL samples, three different patterns were detected: (1) Mac6, PD-1 ${ }^{\text {pos }}$ T8EM, and cDC for two patients (\#3 and \#4) out of seven; (2) Mac3 and Treg cells were increased in one HL patient (\#1); (3) abundance of Mac1, pDC, and T4CM was correlated in four patients (\#2, \#5, \#6, and \#7) out of seven. These patterns were not detected in HD samples. Finally, the mixed cellularity Hodgkin lymphoma was associated with the Mac6 module, T8EM expressing PD-1, and cDC (HL \#3 and \#4). This Mac6 module was not observed in other HL subtypes or other diseases (Table 1 and Fig. 5).

\section{Discussion}

Herein, mass cytometry significantly improved our understanding of the contrasting macrophage phenotypes in DLBCL, FL, and HL tumors. The results here revealed distinct features of macrophages that were associated with B-lymphoma tumor microenvironments. Furthermore, these results emphasize that the phenotypes of macrophages in lymphoma microenvironments are linked to the phenotypes of $\mathrm{T}$ cells in the same tumors. These results suggest that tumors contain distinct immune environments and thus that different immunotherapy strategies will be required to target the distinct macrophage and T-cell subsets observed here.

The mass cytometry panel used here was previously validated in peripheral blood and bone marrow from healthy tissues and in an ex vivo model of myeloid differentiation [22]. Increase in phenotypically distinct macrophage subsets and decrease in pDCs were observed in lymphoma samples when compared to healthy tissues. Systematic analysis identified six macrophages modules representing stable differences in TAM phenotypes observed across lymphoma tumor types. HD macrophages were revealed here to be especially CD64 ${ }^{\text {high }}$ and CD163 ${ }^{\text {low }}$. DLBCL macrophages were $\mathrm{CD} 163^{\text {high }}, \mathrm{CD} 64^{\text {high }}, \mathrm{CD} 32^{\text {high }}, \mathrm{CCR} 2^{\text {high }}$, CD120a ${ }^{\text {high }}$, and S100A9 $9^{\text {high }}$. FL macrophages were CD206 ${ }^{\text {high }}, \mathrm{CD} 6^{\text {high }}$, and CD274 ${ }^{\text {high }}$. Finally, HL macrophages were $\mathrm{CD} 163^{\text {high }}, \mathrm{CD} 64^{\text {high }}, \mathrm{CD} 32^{\text {high }}, \mathrm{CCR} 2^{\text {high }}$, S100A9 ${ }^{\text {high }}$, and CD16 ${ }^{\text {high }}$ HLA-DR ${ }^{\text {low }}$. While CD163 and CD206 were defined as TAM markers in renal cell carcinoma [11], only one of these markers was expressed in DLBCL, FL, or HL. Interestingly, the Mac5 module was characterized by the expression of Slan, which has been previously observed in DLBCL [29]. Besides, TAMs from DLBCLs and HLs were, respectively, S100A9 $9^{\text {high }}$ and S100A9 ${ }^{\text {high }}$ HLA-DR ${ }^{\text {low }}$, a hallmark of MDSCs [3034]. When compared to ex vivo polarized macrophages analyzed with the same panel of antibodies [22], TAMs from DLBCL were most similar to IL-10 polarized macrophages $M \_I L 10\left(\mathrm{CD} 32^{\text {high }} \mathrm{CD} 14^{\text {high }} \mathrm{CCR} 2^{\text {high }} \mathrm{CD} 163^{\text {high }}\right.$ CD64 ${ }^{\text {high }}$ CD $\left.33^{\text {high }}\right)[22,26]$. TAMs from FLs were phenotypically similar to IL-4 polarized macrophages M_IL4 (CD274 $^{\text {high }}$ CD86 ${ }^{\text {high }}$ ). TAMs from HLs were similar to M TPP and in vitro-derived MDSC (CD32 ${ }^{\text {high }}$ CD64 ${ }^{\text {high }}$ CCR2 $2^{\text {high }}$ CD206 ${ }^{\text {high }}$ HLA-DR ${ }^{\text {low }}$ [22]. In agreement with previous studies, TAMs from cHL expressed more PD-L1 (CD274/ programmed death-ligand 1) than in DLBCL $(p<0.01$, data not shown) [35]. The results of this study 
a

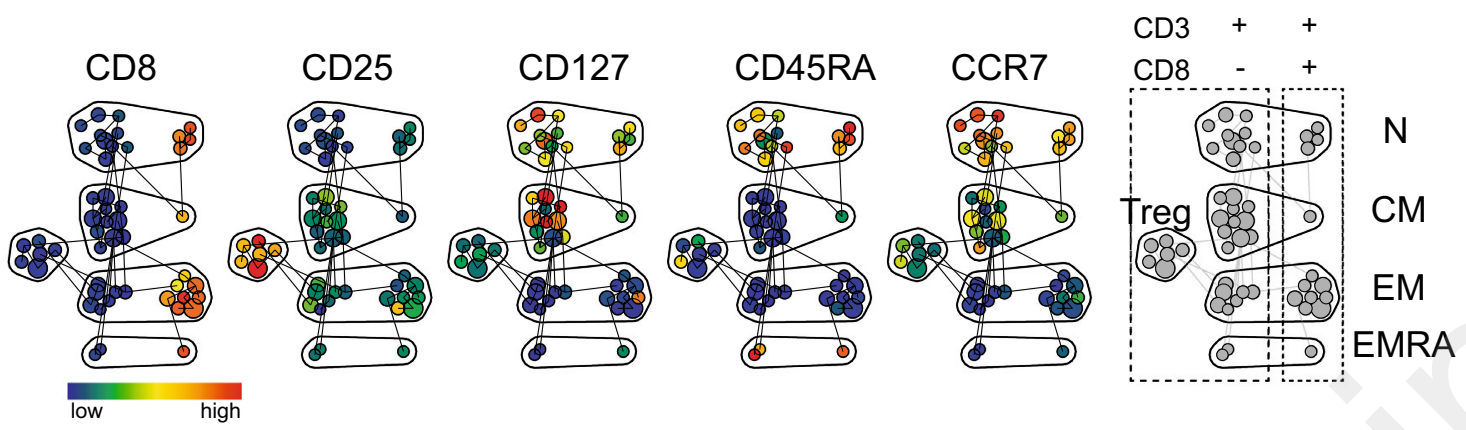

b

CD4
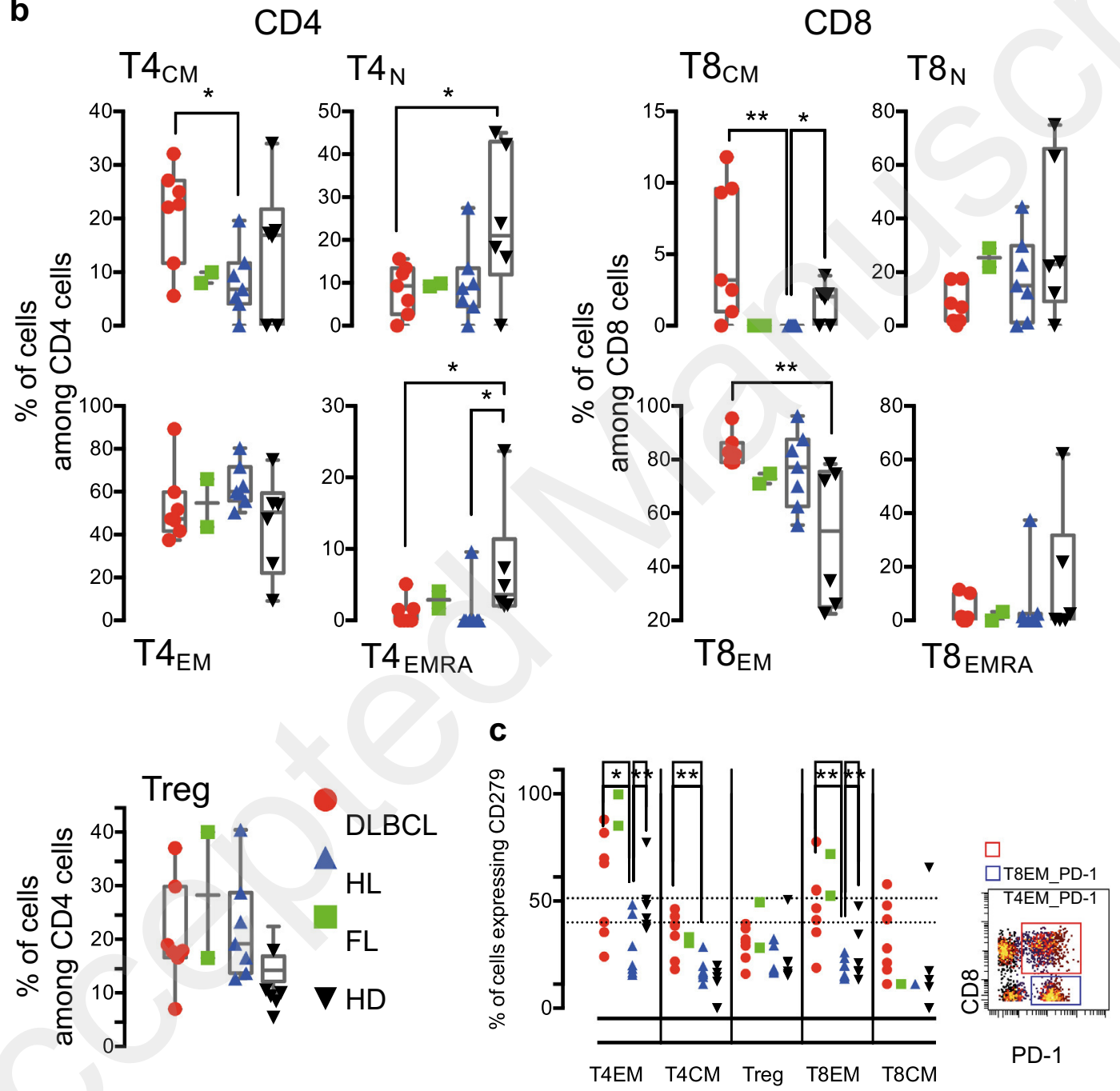

Fig. 4 T-lymphocyte subsets are specific to lymphoma subtypes. a Cell subset identification by SPADE analysis. A representative SPADE is shown. T-cell subsets were defined as follows: $N$ (naïve, CD45RA ${ }^{\text {pos }} \mathrm{CCR}^{\text {pos }}{ }^{\text {}}$ ), CM (central memory, CD45RA ${ }^{\text {neg }} C C R 7^{\text {pos }}$ ), EM (effector memory, CD45RA ${ }^{\text {neg }} C C R 7^{\text {neg }}$ ), EMRA (effector memory expressing CD45RA, CD45RA ${ }^{\text {pos }} C C R 7^{\text {neg }}$ ), and Tregs $\left(\mathrm{CD} 3{ }^{\text {pos }} \mathrm{CD} 8^{\text {neg }} \mathrm{CD} 25^{\text {pos }} \mathrm{CD} 127^{\text {low }}\right)$. b Cell subset frequencies among
CD4 or CD8 cells are shown for DLBCL $(n=7$, red), FL $(n=2$, green), HL ( $n=7$, blue), and HD ( $n=6$, black). c Percentage of T-cell subsets expressing PD-1 among CD4 (EM, CM, and Treg) or CD8 (EM and CM) subsets are shown for DLBCL $(n=7$, red), FL ( $n=2$, green), HL ( $n=7$, blue), and HD ( $n=6$, black). PD- 1 expression on $\mathrm{CM}$ and $\mathrm{EM}$ is shown for a representative sample. ${ }^{*} p<0.05$, $* * p<0.01$ 
indicate that TAMs differ across lymphomas and more than just CD163 will be needed to track and characterize these cells. A high-dimensional approach is well suited to tracking these cells, as more than ten antibodies were needed to effectively capture the lymphoma-specific features of TAMs. Multiple TAM phenotypes coexisted in the typical sample studied here. This might explain why bulk analysis of TAMs from DLBCL samples simultaneously identified both the opposing M1 and M2 signatures [36]. This might also explain the discrepancies in correlation between TAMs and outcomes [21].

T-cell subsets were also revealed and described by the high-dimensional approach. In DLBCL, an increase in T4CM, T8CM and T8EM expressing PD- $1^{\text {high }}$ was noted. In contrast, and as previously published, few T-cell subsets from HLs were observed to express PD-1 [37]. An increase of both effector memory and Tregs in cHL reflecting a proinflammatory and suppressive TME was recently shown [38]. Further, PD-1 ${ }^{\text {pos }}$ T-cell subsets correlated with survival in FL [39].

Altogether, 17 distinct subsets of immune cells were characterized by the single mass cytometry panel here. The DLBCL- and HL-specific phenotypes of lymphomainfiltrating cells were not detected in healthy donor samples. While the results here represent an initial study with a relatively small patient cohort, the cell phenotypes were distinct and consistent enough to reveal lymphomaspecific cell types. Most striking was the Mac6 module that was only observed in mixed cellularity Hodgkin lymphoma. To our knowledge, this is the first immune profiling of the myeloid compartment in lymphoma tumors by mass cytometry. Prior work has characterized $\mathrm{T}$ cells and B cells in FL, DLBCL, and HL using mass cytometry $[38,40,41]$ and characterized myeloid cells in lung and breast cancer $[11,13]$. The resolution of the complex, heterogeneous lymphoma microenvironment by mass cytometry was striking when compared to prior low-dimensional studies measuring fewer than eight markers. The results here indicate that future studies of lymphoma should be single cell, high dimensional (measuring S100A9, CCR2, CD36, Slan, CD32, CD3, CD14, HLA-DR, CD11b, CD11c, CD45RA, CD163, CD68, and CD64), and collect approximately 100,000 CD45 immune cells to effectively describe macrophages in the tumor microenvironment.

There are some key considerations for interpreting the results from this study. First, samples were obtained after mechanical dissociation only, which may preferentially recover some cell subsets [42], however, confirmation of our findings via mIHC would suggest that this possibility was kept to a minimum. Second, the patient cohort represents a pilot study designed to reveal markers and cells to track in future studies. Significantly more patients would be needed to correlate tumor-associated immune cells with well-established histological subtypes or patient outcomes. Third, the mass cytometry panel was designed and validated for myeloid cells and not for $\mathrm{T}$ cells or other immune subsets. However, there were still at least seven markers present that were useful in studying T cells, including CD3, CCR7, CD45RA, CD25, CD127, PD-1, and HLA-DR. To give a broad overview of the TME, it will be interesting to target various myeloid-, stroma-, and T-cell subsets but also to evaluate various immune checkpoints, transcription factors, or signaling pathways. Notably, the complex signature revealed here made it not feasible to sort for TAM subsets or otherwise isolate cells for functional assays. Future studies should seek to define minimal markers for effective isolation of cells for functional studies. Finally, while suspension mass cytometry has substantial benefits for tumor analysis [43], it does necessarily sacrifice tissue architecture and positional information. It will be useful in future studies to get more information on the spatial distribution of cells and cell-to-cell contact. Indeed, recruitment and PDL1 ${ }^{\text {pos }}$ TAM and PD- ${ }^{\text {pos }} \mathrm{T}$ cell subsets have been shown to be in close contact to Reed-Sternberg cells [37]. Thus, it will be interesting to explore TME in lymphomas with imaging mass cytometry and using the panel proposed here [44, 45].

In conclusion, this study provided a starting macrophage atlas for B-cell lymphomas and demonstrated the usefulness of mass cytometry approaches in deciphering the TME and prioritizing markers and cell types for future studies. Notably, canonical macrophage markers CD163 nor CD68 cannot be used solely to define TAMs from lymphomas and future studies should include S100A9, CCR2, CD36, Slan, CD32 along with core macrophage ${ }_{\mathbf{A Q 1}}{ }_{3}$ markers. Going forward, these results allow a better understanding of the biology of tumor macrophages which could be used to optimize the development and application of cancer immunotherapies. 

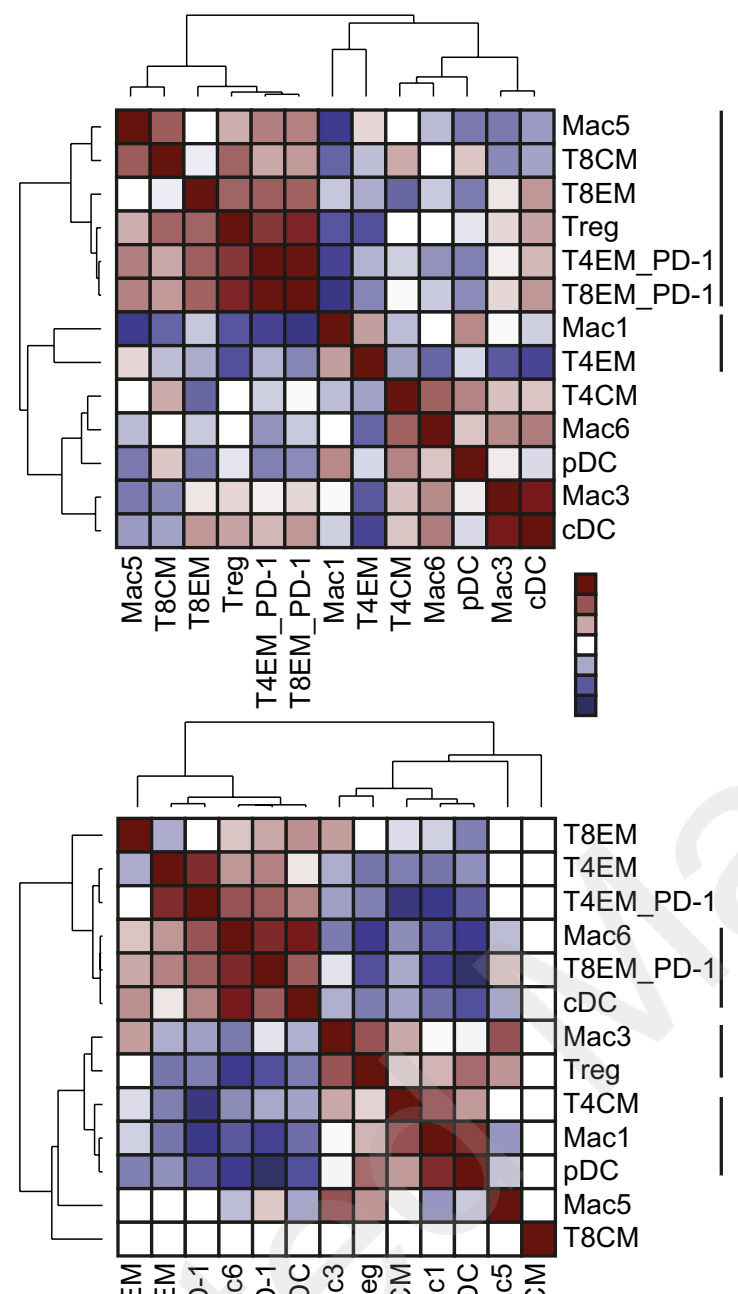

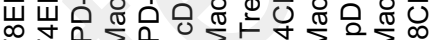

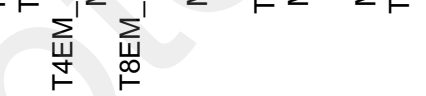
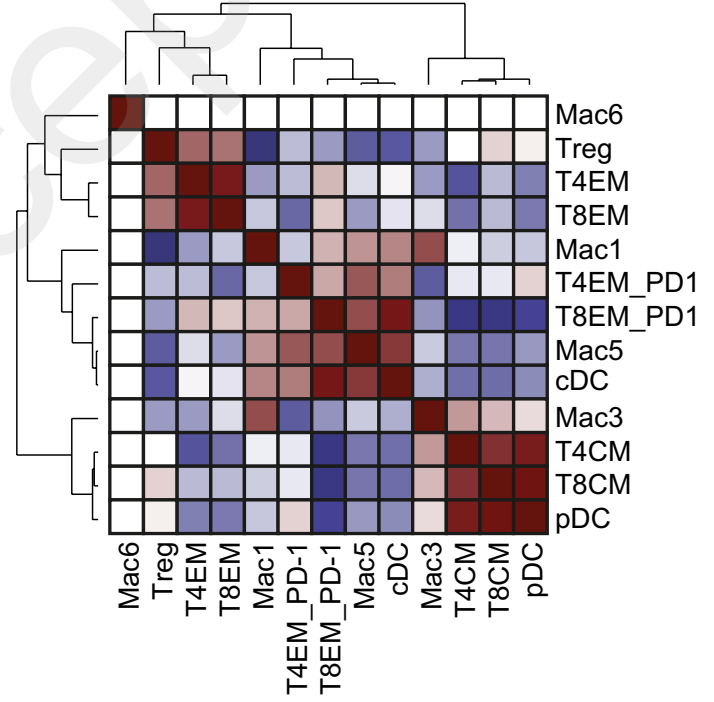
४Fig. 5 Immune cell subsets correlate with each other across lymphoma subtypes. Heatmaps showing Spearman correlation of immune cell population frequencies for DLBCL, HL, or HD. Each identified immune cell subset was correlated with each other defined immune subset infiltrating either DLBCL (top) or HL (bottom). High significant positive correlations are shown in red, while highly significant negative correlations are represented in blue

Acknowledgements We are indebted to the clinicians of the BREHAT (Bretagne Réseau Expertise Hématologie) network and the CeVi collection from the Carnot/CALYM Institute (https://www.calym.org/Collection-de-cellules-vivantes-CeVi-.html) funded by the ANR (Agence Nationale de la Recherche) for providing samples. The authors acknowledge the Centre de Ressources Biologiques (CRB) of Rennes (BB-0033-00056, https://www.crbsante-rennes.com) [Celine Pangault] and the $\mathrm{CeVi}$ network for managing samples.

Author contributions MR and JMI conceived and designed the experiments, analyzed data, and wrote the manuscript; TB and TF analyzed data; MR, FL, CER, PG, and CL performed experiments. All authors revised the manuscript.

Funding This work was supported by research grants: National Institutes of Health/National Cancer Institute (NIH/NCI R00 CA143231, R01 CA226833, U54 CA217450, U01 AI125056), and the VanderbiltIngram Cancer Center (VICC, P30 CA68485) [to Jonathan M. Irish]; Comité pour la recherche translationnelle (CORECT) from the University hospital at Rennes (Grant no. 2015) [to Faustine Lhomme]; and the $\mathrm{CeVi}$ collection from the Carnot/CALYM Institute (ANR) [to Camille Laurent and Mikael Roussel]. Mikael Roussel is recipient of a fellowship from the Nuovo-Soldati Fundation (Switzerland). Pauline Gravelle is supported by the $\mathrm{CeVi}$ collection from the Carnot/CALYM Institute.

\section{Compliance with ethical standards}

Conflict of interest Jonathan M. Irish was a co-founder and was a board member of Cytobank Inc. and received research support from Incyte Corp, Janssen, and Pharmacyclics. The authors declare that there are no other conflicts of interest.

Research sites Sample collection was performed in France (Rennes [all samples except HL \#1, \#2, \#3, and \#4] and through the CeVi_collection [HL \#1, \#, \#3, and \#4]). CyTOF analysis was performed in Nashville, TN, USA by Mikael Roussel during a postdoctoral position in Jonathan Irish's Lab at Vanderbilt University. Data analysis were performed in both sites (Rennes and Nashville). Multiplex IHC was performed in Toulouse (France).

Ethical approval and ethical standards Samples were obtained under French legal guidelines and fulfilled the requirements of the University Hospital of Rennes institutional ethics committee for samples collected in Rennes (CRB) [approval number DC-2008-630 and DC-2016-2565] and of the Comité de Protection des Personnes for samples collected through the Cevi collection [approval number DC-2013-1783].

Informed consent A written consent was obtained from patients before qualification for research in the $\mathrm{CRB}$ or the CeVI collection. The consent was for the use of their specimens and data for research and for publication.

\section{References}

1. Scott DW, Gascoyne RD (2014) The tumour microenvironment in B cell lymphomas. Nat Rev Cancer 14:517-534. https://doi. org/10.1038/nrc3774

2. Galati D, Corazzelli G, De Filippi R, Pinto A (2016) Dendritic cells in hematological malignancies. Crit Rev Oncol Hematol 108:86-96. https://doi.org/10.1016/j.critrevonc.2016.10.006

3. Tudor CS, Bruns H, Daniel C et al (2014) Macrophages and dendritic cells as actors in the immune reaction of classical Hodgkin lymphoma. PLoS One 9:e114345. https://doi.org/10.1371/journ al.pone. 0114345

4. Chang KC, Huang GC, Jones D, Lin YH (2007) Distribution patterns of dendritic cells and T cells in diffuse large B-cell lymphomas correlate with prognoses. Clin Cancer Res 13:6666-6672. https://doi.org/10.1158/1078-0432.CCR-07-0504

5. Mantovani A, Marchesi F, Malesci A et al (2017) Tumour-associated macrophages as treatment targets in oncology. Nat Rev Clin Oncol 14:399-416. https://doi.org/10.1038/nrclinonc.2016.217

6. Xue J, Schmidt SV, Sander J et al (2014) Transcriptome-based network analysis reveals a spectrum model of human macrophage activation. Immunity 40:274-288. https://doi.org/10.1016/j. immuni.2014.01.006

7. Marini O, Spina C, Mimiola E et al (2016) Identification of granulocytic myeloid-derived suppressor cells (G-MDSCs) in the peripheral blood of Hodgkin and non-Hodgkin lymphoma patients. Oncotarget 7:27676-27688. https://doi.org/10.18632/ oncotarget. 8507

8. Azzaoui I, Uhel F, Rossille D et al (2016) T-cell defect in diffuse large B-cell lymphomas involves expansion of myeloid-derived suppressor cells. Blood 128:1081-1092. https://doi.org/10.1182/ blood-2015-08-662783

9. Kumar V, Patel S, Tcyganov E, Gabrilovich DI (2016) The nature of myeloid-derived suppressor cells in the tumor microenvironment. Trends Immunol 37:208-220. https://doi.org/10.1016/j. it.2016.01.004

10. Ugel S, De Sanctis F, Mandruzzato S, Bronte V (2015) Tumorinduced myeloid deviation: when myeloid-derived suppressor cells meet tumor-associated macrophages. J Clin Investig 125:3365-3376. https://doi.org/10.1172/JCI80006

11. Chevrier S, Levine JH, Zanotelli VRT et al (2017) An immune atlas of clear cell renal cell carcinoma. Cell 169:736-738.e18. https://doi.org/10.1016/j.cell.2017.04.016

12. Wagner J, Rapsomaniki MA, Chevrier S et al (2019) A single-cell atlas of the tumor and immune ecosystem of human breast cancer. Cell. https://doi.org/10.1016/j.cell.2019.03.005

13. Lavin Y, Kobayashi S, Leader A et al (2017) Innate Immune landscape in early lung adenocarcinoma by paired single-cell analyses. Cell 169:750-757.e15. https://doi.org/10.1016/j.cell.2017.04.014

14. Riihijarvi S, Fiskvik I, Taskinen M et al (2015) Prognostic influence of macrophages in patients with diffuse large B-cell lymphoma: a correlative study from a nordic phase II trial. Haematologica 100:238-245. https://doi.org/10.3324/haema tol.2014.113472

15. Hasselblom S, Hansson U, Sigurdardottir M et al (2008) Expression of CD68 tumor-associated macrophages in patients with diffuse large B-cell lymphoma and its relation to prognosis. Pathol Int 58:529-532. https://doi.org/10.1111/j.1440-1827.2008.02268 .x

16. Shen L, Li H, Shi Y et al (2016) M2 tumour-associated macrophages contribute to tumour progression via legumain remodelling the extracellular matrix in diffuse large B cell lymphoma. Sci Rep 6:30347. https://doi.org/10.1038/srep30347

17. Aldinucci D, Celegato M, Casagrande N (2016) Microenvironmental interactions in classical Hodgkin lymphoma and their 
role in promoting tumor growth, immune escape and drug resistance. Cancer Lett 380:243-252. https://doi.org/10.1016/j.canle t.2015.10.007

18. Greaves P, Clear A, Owen A et al (2013) Defining characteristics of classical Hodgkin lymphoma microenvironment T-helper cells. Blood 122:2856-2863. https://doi.org/10.1182/blood-2013-06508044

19. Steidl C, Lee T, Shah SP et al (2010) Tumor-associated macrophages and survival in classic Hodgkin's lymphoma. N Engl J Med 362:875-885. https://doi.org/10.1056/NEJMoa0905680

20. Azambuja D, Natkunam Y, Biasoli I et al (2012) Lack of association of tumor-associated macrophages with clinical outcome in patients with classical Hodgkin's lymphoma. Ann Oncol 23:736742. https://doi.org/10.1093/annonc/mdr157

21. Kridel R, Steidl C, Gascoyne RD (2015) Tumor-associated macrophages in diffuse large B-cell lymphoma. Haematologica 100:143-145. https://doi.org/10.3324/haematol.2015.124008

22. Roussel M, Ferrell PB, Greenplate AR et al (2017) Mass cytometry deep phenotyping of human mononuclear phagocytes and myeloid-derived suppressor cells from human blood and bone marrow. J Leukoc Biol 102:437-447. https://doi.org/10.1189/ jlb.5MA1116-457R

23. Fienberg HG, Simonds EF, Fantl WJ et al (2012) A platinumbased covalent viability reagent for single-cell mass cytometry. Cytom A 81:467-475. https://doi.org/10.1002/cyto.a.22067

24. Finck R, Simonds EF, Jager A et al (2013) Normalization of mass cytometry data with bead standards. Cytom A 83:483-494. https ://doi.org/10.1002/cyto.a.22271

25. Diggins KE, Ferrell PB, Irish JM (2015) Methods for discovery and characterization of cell subsets in high dimensional mass cytometry data. Methods 82:55-63. https://doi.org/10.1016/j. ymeth.2015.05.008

26. Roussel M, Bartkowiak T, Irish JM (2019) Picturing polarized myeloid phagocytes and regulatory cells by mass cytometry. Methods Mol Biol 1989:217-226. https://doi. org/10.1007/978-1-4939-9454-0_14

27. Kotecha N, Krutzik PO, Irish JM (2010) Web-based analysis and publication of flow cytometry experiments. Curr Protoc Cytom. https://doi.org/10.1002/0471142956.cy1017s53

28. Gravelle P, Péricart S, Tosolini M et al (2018) EBV infection determines the immune hallmarks of plasmablastic lymphoma. Oncoimmunology 7:e1486950. https://doi.org/10.1080/21624 02X.2018.1486950

29. Vermi W, Micheletti A, Finotti G et al (2018) slan+ monocytes and macrophages mediate CD20-dependent B-cell lymphoma elimination via ADCC and ADCP. Can Res 78:3544-3559. https ://doi.org/10.1158/0008-5472.CAN-17-2344

30. Bronte V, Brandau S, Chen S-H et al (2016) Recommendations for myeloid-derived suppressor cell nomenclature and characterization standards. Nat Commun 7:12150. https://doi.org/10.1038/ ncomms 12150

31. Feng P-H, Lee K-Y, Chang Y-L et al (2012) CD14(+)S100A9(+) monocytic myeloid-derived suppressor cells and their clinical relevance in non-small cell lung cancer. Am J Respir Crit Care Med 186:1025-1036. https://doi.org/10.1164/rccm.201204-0636OC

32. Zhao F, Hoechst B, Duffy A et al (2012) S100A9 a new marker for monocytic human myeloid-derived suppressor cells. Immunology 136:176-183. https://doi.org/10.1111/j.1365-2567.2012.03566.X
33. Chen X, Eksioglu EA, Zhou J et al (2013) Induction of myelodysplasia by myeloid-derived suppressor cells. J Clin Investig 123:4595-4611. https://doi.org/10.1172/JCI67580

34. Feng P-H, Yu C-T, Chen K-Y et al (2018) S100A9+ MDSC and TAM-mediated EGFR-TKI resistance in lung adenocarcinoma: the role of RELB. Oncotarget 9:7631-7643. https://doi.org/10.18632 /oncotarget. 24146

35. Vari F, Arpon D, Keane C et al (2018) Immune evasion via PD-1/ PD-L1 on NK cells and monocyte/macrophages is more prominent in Hodgkin lymphoma than DLBCL. Blood 131:1809-1819. https://doi.org/10.1182/blood-2017-07-796342

36. McCord R, Bolen CR, Koeppen H et al (2019) PD-L1 and tumorassociated macrophages in de novo DLBCL. Blood Adv 3:531540. https://doi.org/10.1182/bloodadvances.2018020602

37. Carey CD, Gusenleitner D, Lipschitz M et al (2017) Topological analysis reveals a PD-L1-associated microenvironmental niche for Reed-Sternberg cells in Hodgkin lymphoma. Blood 130:24202430. https://doi.org/10.1182/blood-2017-03-770719

38. Cader FZ, Schackmann RCJ, Hu X et al (2018) Mass cytometry of Hodgkin lymphoma reveals a CD4+ regulatory T-cell-rich and exhausted T-effector microenvironment. Blood 132:825-836. https://doi.org/10.1182/blood-2018-04-843714

39. Yang Z-Z, Kim HJ, Villasboas JC et al (2019) Mass cytometry analysis reveals that specific intratumoral CD4+ T cell subsets correlate with patient survival in follicular lymphoma. Cell Rep 26:2178-2193.e3. https://doi.org/10.1016/j.celrep.2019.01.085

40. Wogsland CE, Greenplate AR, Kolstad A et al (2017) Mass cytometry of follicular lymphoma tumors reveals intrinsic heterogeneity in proteins including HLA-DR and a deficit in nonmalignant plasmablast and germinal center B-cell populations. Cytom B Clin Cytom 92:79-87. https://doi.org/10.1002/cyto.b.21498

41. Nissen MD, Kusakabe M, Wang X et al (2019) Single cell phenotypic profiling of 27 DLBCL cases reveals marked intertumoral and intratumoral heterogeneity. Cytom A 9:2579. https://doi. org/10.1002/cyto.a.23919

42. Leelatian N, Doxie DB, Greenplate AR et al (2017) Single cell analysis of human tissues and solid tumors with mass cytometry. Cytom B Clin Cytom 92:68-78. https://doi.org/10.1002/ cyto.b. 21481

43. Mistry AM, Greenplate AR, Ihrie RA, Irish JM (2018) Beyond the message: advantages of snapshot proteomics with single-cell mass cytometry in solid tumors. FEBS J. https://doi.org/10.1111/ febs. 14730

44. Giesen C, Wang HAO, Schapiro D et al (2014) Highly multiplexed imaging of tumor tissues with subcellular resolution by mass cytometry. Nat Methods 11:417-422. https://doi.org/10.1038/ nmeth.2869

45. Chang Q, Ornatsky OI, Siddiqui I et al (2017) Imaging mass cytometry. Cytom A 91:160-169. https://doi.org/10.1002/ cyto.a. 23053

Publisher's Note Springer Nature remains neutral with regard to jurisdictional claims in published maps and institutional affiliations. 